\title{
Cerebellar dermoid cysts with hydrocephalus
}

\author{
Bayram Çırak ${ }^{1}$, Nejmi Kıymaz ${ }^{2}$, Memduh Kerman ${ }^{3}$ \\ ${ }^{1}$ Department of Neurosurgery, Pamukkale University, School of Medicine, Denizli, Turkey, \\ ${ }^{2}$ Department of Neurosurgery, Yüzüncü Yll University, School of University, Van, Turkey, \\ ${ }^{3}$ Health Ministry Hospital, Isparta, Turkey
}

\begin{abstract}
Intracranial dermoid cyst is a rare entity, accounting less than $1 \%$ of all intracranial tumors. The most common localization is midline at the posterior fossa. They usually cause symptoms related to compression, infection, hydrocephalus, or a combination of all. The controversy arises about the preoperative treatment planning. Since infection is a major risk in those patients, inserting a shunt at the same session of tumor removal may not be achieved. Total resection of tumor is a must. We present two cases of posterior fossa dermoid cysts with hydrocephalus as a complication. First case presented with the symptoms of meningitis. She had no hydrocephalus at the time of surgery. The second case had hydrocephalus but no sign of infection. Both cases needed ventriculoperitoneal shunt insertion. Hydrocephalus may occur at any time during the course of the disease. But appropriate time of handling is important to avoid increased morbidity and mortality related to the shunt infection failure. (J Pediatr Neurol 2004; 2(3): 161-164).
\end{abstract}

Key words: cerebellar tumor, dermoid cyst, hydrocephalus, posterior fossa tumor.

\section{Introduction}

Intracranial dermoid cysts are usually slow growing and relatively rare congenital tumors. They are believed to arise from the germinal layers at about fourth week of gestation. Although $7 \%$ of

Correspondence: Bayram Çırak M.D.

Fatih Mah. Fevzi Çakmak Blv. No. 119/2

Denizli, Turkey.

Tel: +90 258 2664039, fax: +902582633129.

E-mail: bayramcirak@yahoo.com

Received: March 02, 2004

Revised: April 28, 2004.

Accepted: April 29, 2004. dermoids occur in head and neck. Posterior fossa is a rare but recognized site for development of dermoid (1). Dermoid cyst has to be differentiated from epidermoid. Dermoid wall and content include cutaneous appendages, namely hair, sweet and sebaceous glands, and their products, all which are different than epidermoid, which contains only desquamated cells from epidermal layer. Typical localization of epidermoid is skull base and cerebellopontine angle whereas dermoids prefer midline either in the spine or cranial region $(2,3)$. Although, computerized tomography (CT) and magnetic resonance imaging (MRI) have facilitated the diagnosis of these tumors, there remains a degree of controversy regarding preoperative treatment planning $(4,5)$. In an extensive survey of the literature about the dermal cysts revealed that almost all of the articles are about the infectious potential of the dermal cysts $(6,7)$. There is not convincing knowledge about the hydrocephalus and treatment of hydrocephalus in patients with posterior fossa dermal cysts. Here we presented two cases of dermoid cysts associated with infection and hydrocephalus.

\section{Case 1}

A 2.5-year-old girl was admitted to the pediatric emergency with the complaining fever, nausea and vomiting. After a physical examination and routine laboratory screening she has been hospitalized with the diagnosis of meningitis. She had no stigmata on the skin such as fistula or sinus. She has been put on vancomycin and amikacin treatment. But, since her complaints continued she had underwent radiologic examination of the cranium including CT and MRI. She was then referred to neurosurgery clinic with the radiologic diagnosis of a posterior fossa mass lesion on the MRI, a regular shaped enhancing lesion in the midline posterior fossa behind the fourth ventricle was seen without hydrocephalus (Figure 1). She underwent an operation with the possible diagnosis of posterior fossa abscess or congenital tumor. Through a median suboccipital craniotomy, a hair filled dermoid cyst was totally 


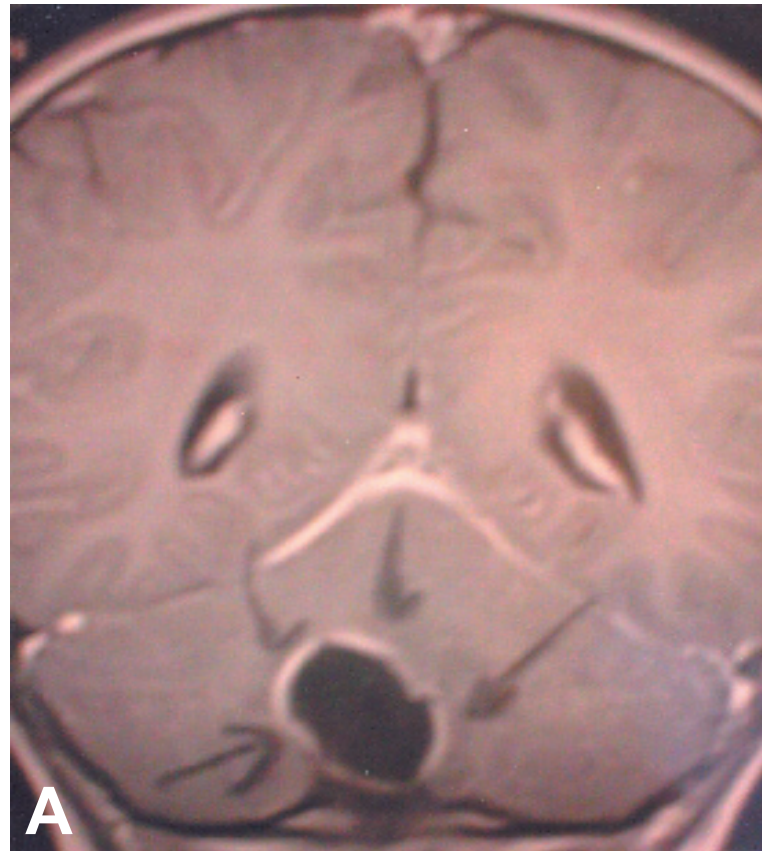

resected. Her postoperative period was uneventful. She was discharged on the seventh postoperative day well with no neurological deficit. Three months later she came back with the complaint of ataxia and urinary incontinence. A cranial CT demonstrated nonobstructive hydrocephalus. There was no recurrence and regrowth of the dermoid cyst. A ventriculo-peritoneal shunt was inserted; ventricular opening pressure was over $20 \mathrm{~cm} \mathrm{H}_{2} \mathrm{O}$. Her postoperative follow up one year later revealed a normal neurological examination.

\section{Case 2}

A 3-year-old girl was admitted to the neurosurgery clinic with the complaint of ataxia, and nausea for 15 days. Physical and neurological examination revealed a small dimple in the midline just below the external occipital protuberantia without drainage and ataxia on walking. There was no drainage through the dimple. She underwent a radiologic evaluation including cranial CT and MRI, which disclosed a posterior fossa mass lesion and hydrocephalus (Figure 2). She has been operated on. Intraoperatively, a dermal sinus, which ended blindly in the subcutaneous layer, just below the dimple on the skin was noticed. It was found to be connected to the mass lesion and thereby resected. The tumor was filled with hair. The wall of the dermoid was adhered tightly to the fourth ventricle wall and could not be dissected thoroughly and a small piece of the capsule was left behind. At the same session a ventriculo-peritoneal shunt was inserted after ruling out abnormal biochemical and microbiological parameters in the cerebrospinal fluid (CSF). Histopathologically it was reported as dermoid

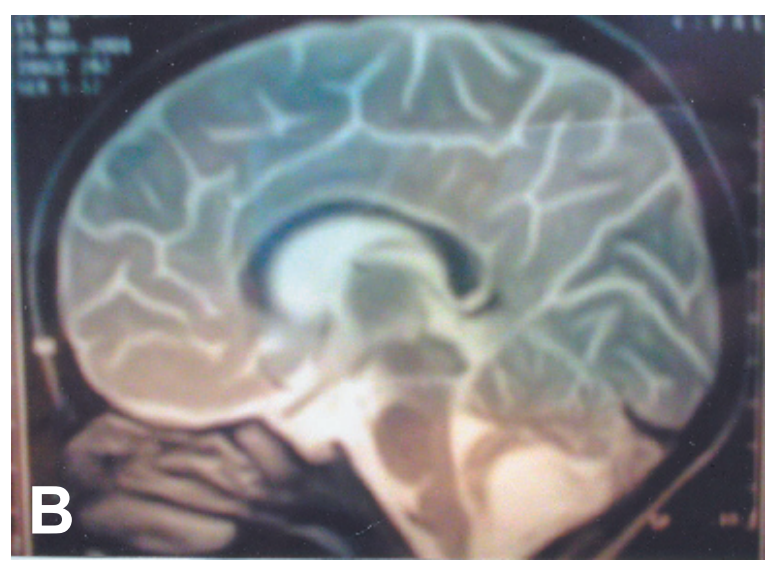

Figures 1a and 1b. T1W postcontrast coronal and T2W sagittal MRI sections of the posterior fossa show dermoid cyst.

cyst. She had a good postoperative recovery and was discharged on the 10th postoperative day. There was no neurological abnormality on follow up for one year.

\section{Discussion}

Intracranial dermoid cyst is a rare entity, accounting between $0.1 \%$ and $0.7 \%$ of all intracranial tumors. Dermoids usually become symptomatic during childhood or early adulthood $(8,9)$. One of the most vulnerable stages of intrauterine life is between the third and fifth weeks, when the embryo is at risk of separation of the neuroectoderm from the epithelial ectoderm. Dermoids originate from misplaced ectoderm during this stage. Dermoid cysts contain cutaneal appendages, hair follicles, sweat and sebaceous glands. Dermoid cysts are benign lesions and grow slowly as a result of the secretion of the sebaceous material and desquamation of the epithelium. The midline at the posterior fossa vermis and spine are the most common predilection sites for dermoid cysts. They can be extra or intradural. Rarely, dermoid cyst may extend to the level of skin producing a coexisting dermal sinus. This tube contains the glandular architecture of skin and favourizes colonization of microorganisms. Through this tube there is always a potential risk of central nervous system (CNS) infection (10-13). Tekkök et al. (7) reviewed the abscedetion (abscess formation) of posterior Fossa dermoid cysts very extensively. They discussed the key issues on the appropriate management of infected dermoids and concluded the complete resection with an experienced surgeon would prevent leptomeningeal spread of infection. Dermoid cysts may cause recurrent bacterial 


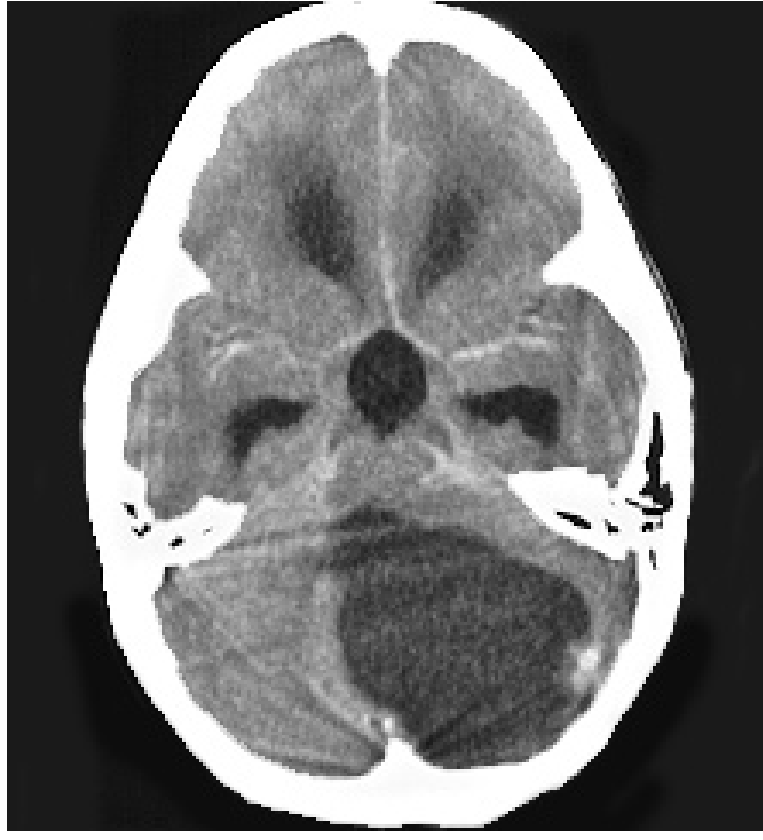

Figure 2. Axial CT section of the posterior fossa showing dermoid cyst.

meningitis in childhood, due to infection via dermoid sinus $(11,12,14)$. Recurrent meningitis or meningitis, which does not change its course with the medical treatment, must warn the physician about the dermoid cysts.

Intracranial dermoids may also enlarge and cause direct pressure effects on surrounding brain structures or cranial nerves. In these cases compressive signs or signs and symptoms of raised intracranial pressure predominates $(2,9)$. There may be cerebellar dysfunction, trigeminal neuralgia or hemifacial spasm like symptomatology (5).

Today, preoperative diagnosis is possible by using CT and MRI in conjunction. CT shows a low density mass with values of around-100 HU (Hounsfiel Unit) without capsular enhancement. Almost all reported cases have demonstrated short T1 values on MRI with corresponding high signal intensity on T1 weighted images. The presence of infection or abscess formation causes enhancement both in the CT and MRI $(4,15)$.

Microsurgical resection of the tumor is the choice of treatment in dermoid cysts. Total resection should be the main goal but may not be achieved in all cases. The dermoid tumors particularly display dense reactive involvement of the arachnoid and occasionally of the pia mater. Rarely, the infiltration is too extensive and involves vital structures, which cannot be sacrificed. In those cases, some pieces of capsule may be left. The rate of growth in those cases will be sufficiently slow to obviate further treatment $(5,16)$. In our second case, we also could not manage to dissect the capsule completely and left some pieces adherent to the 4th ventricle wall.
She had no progress of disease in 3 years follow up.

Comparing the infectious symptoms and signs of dermal cysts hydrocephalus and related signs and symptoms got less interest in the literature. Development of hydrocephalus in dermal cyst may be the second most common presentation after the infection. Hydrocephalus may be present at the time of diagnosis of dermoid cyst due to compression of the CSF leakage or it may develop secondary to infection. The important thing about planning the ventriculo-peritoneal shunt treatment is the presence or absence of CNS infection. There are three types of scene in dermoid cyst patients about the hydrocephalus treatment. First one is, if the hydrocephalus is present at the time of dermoid cyst diagnosis together with infection of the CNS. An external drainage should be useful at the same session of the dermoid cyst removal. The second type is, if there is not any sign and symptom of infection at the surgery time, as it is in our second case, is sure that CSF is clear of bacterial contamination. For this reason a perioperative evaluation of the CSF will be helpful. If the CSF is clear insertion of the ventriculo-peritoneal shunt should be thought at the very end of surgical removal of the dermoid cyst. Because there is always danger of CSF contamination or rupture of the cyst into the ventricles during surgery. To prevent this, surgeon should aim at en bloc microsurgical removal of the lesion. He should also anticipate the possibility of postoperative meningitis and prescribe broadspectrum intravenous antibiotics intraoperatively. Since there is no relevant literature about the subject, we do not know whether use of an external drainage in non-infected dermoid cyst patients will be safe for postoperative period, and then inserting a ventriculo-peritoneal shunt in another surgical session. The third and the last type is, if hydrocephalus developed postsurgically during follow up period, as it is in our first case, ventriculoperitoneal shunt insertion should be thought after the evaluation of the CSF for infection. There have been very few publications about the long-term outcome of dermoid cyst patients. Lunardi et al. $(2,9)$ reported a mean follow-up of 17.3 years with complete long-term freedom from tumor recurrence in all patients even in the child in whom a small portion of the tumor capsule was left adherent to the floor of the fourth ventricle.

Posterior fossa dermoid cysts are rare. Hydrocephalus, meningitis and sometimes cerebellar abscesses are the principal manifestations. Posterior fossa dermoid cysts should be considered in all children with recurrent meningitis and in children with occipital skin lesions, especially dermal sinus. CT scan and MRI are the methods of choice for further investigation of suspect congenital dermal lesions. Neurosurgical 
treatment of these malformations should be planned early to prevent the high incidence of infections such as bacterial meningitis and cerebellar abscess. Preoperative surgical planning of operation time and type for the hydrocephalus associated with posterior fossa dermoid cysts is also utmost importance. In cases where total resection of the dermoid cyst is unachieved, recurrent meningitis and shunt failure rates increase.

\section{References}

1. Cobbs CS, Pitts LH, Wilson CB. Epidermoid and dermoid cysts of the posterior fossa. Clin Neurosurg 1997; 44: 511-528.

2. Lunardi P, Missori P, Gagliardi FM, Fortuna A. Dermoid cysts of the posterior cranial fossa in children. Report of nine cases and review of the literature. Surg Neurol 1990; 34: 39-42.

3. Uppal HS, D'Souza AR, De R, Irving RM. Dermoid cyst of the infratemporal fossa. J Laryngol Otol 2002; 116: 150-152.

4. Goh GJ, Page RD, Nixon TE. An unusual CT and MR appearance of a posterior fossa dermoid. Eur $\mathrm{J}$ Radiol 1995; 20: 46-47.

5. Guidetti B, Gagliardi FM. Epidermoid and dermoid cysts. Clinical evaluation and late surgical results. J Neurosurg 1977; 47: 12-18.

6. Erdem G, Topaloğlu H. Abscess formation in posterior fossa with dermoid cyst. Child's Nerv Syst 1997; 13: 297.

7. Tekkök IH, Baesa SS, Higgins MJ, Ventureyra EC. Abscedation of posterior dermoid cysts. Child's Nerv Syst 1996; 12: 318-322.
8. Aksoy FG, Aksoy OG, Gomori JM. Klippel-Feil syndrome in association with posterior fossa suboccipital dermoid cyst. Eur Radiol 2001; 11: 142144.

9. Lunardi P, Missori FM, Gagliardi FM, Fortuna A. Dermoid and epidermoid cysts of the midline in the posterior fossa. Neurosurg Rev 1992; 15: 171-175.

10. Hayek G, Mercier P, Fournier HD, Menei P, Pouplard F, Guy G. Dermal sinus and dermoid cyst revealed by abscess formation in the posterior fossa. Report of 2 pediatric cases and review of the literature. Neurochirurgie 2001; 47: 123-127 (in French).

11. Peter JC, Sinclair-Smith C, de Villiers JC. Midline dermal sinuses and cysts and their relationship to the central nervous system. Eur J Pediatr Surg 1991; 1: 73-79.

12. Vieira T, Eppes SC, Magram G. Recurrent E. coli meningitis associated with an intracranial dermoid cyst. Clin Pediatr 1996; 35: 32-33.

13. Wilms G, Plets C, Marchal G, Demaerel P. Simultaneous occurrence of epidermoid and dermoid cysts in the posterior fossa: CT and MR findings. AJNR Am J Neuroradiol 1990; 11: 1257-1258.

14. Ecker RD, Atkinson JL, Nichols DA. Delayed ischemic deficit after resection of a large intracranial dermoid: case report and review of the literature. Neurosurgery 2003; 52: 706-710.

15. Brown JY, Morokoff AP, Mitchell PJ, Gonzales MF. Unusual imaging appearance of an intracranial dermoid cyst. AJNR Am J Neuroradiol 2001; 22: 1970-1972.

16. Yaşargil MG, Abernathey CD, Sarığlu AC. Microneurosurgical treatment of intracranial dermoid and epidermoid tumors. Neurosurgery 1989; 24 : 561-567. 